\title{
Teaching Young Learners English Vocabulary with Reading-Based Exercises in a Real Classroom Situation
}

\author{
MA, QING \\ The Hong Kong Institute of Education, Hong Kong \\ SIN, CHING HA \\ Christian Alliance S. Y. Yeh Memorial School, Hong Kong
}

\begin{abstract}
This classroom study investigated how English (L2) vocabulary was taught to primary school pupils in a series of reading lessons under two conditions: (a) reading plus receptive learning exercises or (b) reading plus both receptive and productive learning exercises. The results showed that the condition involving both receptive and productive exercises led to more vocabulary retention than the condition with receptive exercises only. Furthermore, it is tentatively proposed that young learners' productive knowledge of vocabulary items can be assessed based on acceptable collocations instead of sentence writing which relies on a fully developed grammar system that young learners may lack.

Keywords: vocabulary acquisition/instruction, young learners, receptive exercises, productive exercises, vocabulary learning difficulties
\end{abstract}

La enseñanza de vocabulario inglés a jóvenes aprendices con ejercicios diseñados a partir de textos de comprensión lectora en una situación real de aula

RESUMEN: Este estudio práctico en el ámbito del aula investigó cómo se enseñaba el vocabulario inglés (L2) a alumnado de primaria en una secuencia de unidades didácticas de textos de comprensión lectora estableciendo dos situaciones: (a) lectura más ejercicios de aprendizaje a nivel receptivo, o (b) lectura más ejercicios de aprendizaje tanto a nivel receptivo como productivo. Los resultados de la investigación muestran que la situación que incluye ejercicios tanto a nivel receptivo como productivo lleva a una mayor retención de vocabulario que la que considera únicamente ejercicios a nivel receptivo. Además, se propone de manera tentativa que el conocimiento de vocabulario a nivel productivo de los aprendices jóvenes se puede evaluar basándose en la producción de colocaciones correctas en lugar de frases escritas que dependen de un sistema gramatical altamente desarrollado del que los aprendices jóvenes pueden carecer.

Palabras claves: adquisición/instrucción de vocabulario, aprendices jóvenes, ejercicios a nivel receptivo, ejercicios a nivel productivo, dificultades de aprendizaje de vocabulario

\section{INTRODUCTION}

In recent years FL or L2 vocabulary acquisition tends to be investigated in a reading context (Pellicer-Sánchez and Schmitt, 2010; Waring and Donkaewbua, 2008; Horst, 2005; Hill and Laufer, 2003), which is frequently associated with incidental learning modelled on L1 acquisition. It is widely believed that children acquire most L1 vocabulary through 
extensive listening or reading and their main focus is on understanding the message being conveyed rather than on the new words encountered (Nagy, Herman and Anderson 1985; Sternberg 1987). Extending this notion to FL or L2 acquisition, researchers have investigated to what extent adults, especially university students or the equivalent, learn vocabulary in different reading contexts (see Pitts, White and Krashen, 1989; Mason and Krashen, 1997; Horst, Cobb and Meara, 1998; Horst 2005; Pellicer-Sánchez and Schmitt, 2010; Laufer and Rozovski-Roitblat, 2011). Although children's L2 acquisition is supposed to be closely associated with their L1 acquisition, there has been relatively little interest in how they acquire L2 vocabulary in reading, particularly in classroom settings.

It is generally agreed that pure incidental L2 learning from reading on its own is not as effective as previously expected (Huckin and Coady, 1999; Laufer, 2006; Sonbul and Schmitt, 2010). Reading plus explicit focus on target items, i.e. using vocabulary exercises, has been proposed as an alternative to address the drawbacks in incidental learning by a number of researchers (Paribakht and Wesche, 1997; Hill and Laufer, 2003; Min, 2008; Laufer and Rozovski-Roitblat, 2011). Vocabulary knowledge is invariably classified as receptive and productive, i.e. retrieving the meaning of a word in listening or reading as opposed to producing it in speaking and writing (Nation, 2001). Vocabulary exercises can be broadly divided accordingly, depending on which type of knowledge is aimed for. Previous studies on reading-based vocabulary exercises typically employ both types of exercises or focus on only one type, whereas very few studies have investigated the learning effect of each separately for either adult or young learners. This teacher-led classroom research can shed light on young learners' L2 vocabulary acquisition as well as offer practical suggestions for primary school English teachers to make vocabulary instruction more efficient in the most common classroom learning context when reading materials are used.

\section{Theoretical foundations}

\subsection{Vocabulary Acquisition through Reading}

Similar to L1 acquisition, reading is believed to be one of the most important resources for acquiring L2 vocabulary in an incidental manner. Incidental learning occurs as a result of a number of exposures to unknown items during the reading process, meaning being obtained by either guessing or consulting a dictionary (Hulstijn, 2005). Although the role of reading in second language vocabulary learning is widely accepted, there are several limitations to this approach. First, guessing from the reading context may be inaccurate, time-consuming and cognitively demanding (Huckin and Coady, 1999). Even when a dictionary is consulted, the learner may soon forget more than half of the words (Hulstijn, Hollander and Greidanus, 1996). Studies suggest that incidental learning typically yields vocabulary gains in meaning recognition only but not in production (Pitts et al., 1989; Horst et al., 1998). Secondly, researchers generally agree that vocabulary retention rate is rather low; the average gain ranges from 1 to 5 words per text (Pitts et al., 1989; Knight, 1994; Paribakht and Wesche, 1997; Horst et al., 1998). One of the reasons why the learning process is so slow is that multiple exposures to target words are required. Waring and Takaki (2003) proposed 8 encounters with the target item as the minimum figure to ensure retention. In a similar vein, 
Brown, Waring, and Donkaewbua (2008) concluded that 7-9 encounters are necessary for acquisition and to reduce attrition. A recent study by Pellicer-Sánchez and Schmitt (2010) shows that 5-8 exposures to target items are needed for incidental learning to occur and $10-17$ can accelerate the learning.

\subsection{Text-based Vocabulary Learning Exercises}

In response to the main drawbacks associated with pure incidental learning, additional vocabulary activities/exercises are considered an important means for enhancing learners' vocabulary learning and have been traditionally valued in classroom teaching. In reading, the learner might notice an unknown word and try to access its meaning, but may pay little attention to the word form because it is meaning that is important for text comprehension. While doing vocabulary exercises, learners' attention can be more directly attuned to the form of target items. There are two types of text-based vocabulary exercises: one is fully contextualized and the other semi-contextualized. The difference lies in the length of the reading context on which the exercises are based.

\subsubsection{Fully contextualized reading-based exercises}

Given the limitations of acquiring vocabulary through reading only, a number of researchers have suggested an alternative approach: reading plus exercises. Paribakht and Wesche (1997) compared the effects of two different kinds of vocabulary instruction, reading only and reading plus word-focused exercises, ranging from noticing to producing the target item. A group of university students learning English as an L2 participated in the study and experienced both conditions. The Vocabulary Knowledge Scale (VKS), measuring five types of knowledge from no knowledge to being able to use the word both grammatically and semantically correctly in a sentence, was used to measure the vocabulary retention. It was found that, although both approaches resulted in important gains in learners' vocabulary knowledge, the reading plus condition yielded a greater vocabulary retention. More specifically, the words learned in the reading only condition tend to remain at the recognition level, whereas many words learned in the reading plus condition moved to a higher level of knowledge, e.g. from receptively known to productively known. Min (2008) adopted a similar procedure and obtained similar results.

A recent study by Laufer and Rozovski-Roitblat (2011) adopted a more complex design in which the effect of both reading type and number of word occurrences was measured. There are two task conditions: the "focus on form" condition is to expose readers to the target words through reading, and the "focus on forms" condition is reading exposure plus different word-focused exercises. The target words occurred 2-3, 4-5, 6-7 times in the reading and exercises. Only the word meaning was tested in this study, showing that the reading plus word-focused exercises outperformed the reading alone condition when words occurred four times or more in both meaning recognition and call. However, even when readers were exposed to the target words 6-7 times, the maximum meaning retention was only $63.5 \%$ for recognition and $34.5 \%$ for recall. This shows that reading plus a considerable number of encounters with the target words in word-focused exercises mainly leads to meaning recognition and less favorably to meaning recall. It is assumed that the retention rate for form production would be even lower. 


\subsubsection{Semi-contextualized exercises}

Not all vocabulary exercises are based on a fully contextualised reading text. Sometimes the target items to be practised are simply embedded in one or two sentences while the contextual information is much less rich than that in the reading text. For example, Folse (2004) designed three types of such sentence-based exercises: meeting the target word in one fill-in-the-blank exercise, meeting the target word in three fill-in-the-blank exercises and writing a self-created sentence containing the word, all types being productive in nature. A modified VKS was used to measure the knowledge gain of university students, showing that the three-exercise condition was superior to the other two conditions, leading to the conclusion that word retention hinges upon the number of word retrievals while the efforts made in creating sentences, associated with depth of processing, is less crucial.

Webb (2005) compared university students' receptive and productive learning effects. In the receptive task the learner was given a word pair (L2 with L1 definition) plus three sentences containing the target word, which serve as additional glosses and the learner were asked to learn the L2 words. In the productive task the word pair was followed by a sentence-making exercise. A range of tests were employed to measure learners' vocabulary gain in form, meaning (basic and associative) and use (receptive and productive). A between-subjects design, in which sufficient time was given to each condition, showed that the receptive condition was superior to the productive condition. A second within-subjects design, in which only the time needed was given to each condition (but longer time for the productive task due to its nature), revealed that the productive condition was more effective. Webb (2005: 50) argued that the second experimental design represents more authentic learning and claimed: "productive learning is superior to receptive learning not only in developing productive knowledge but also in producing larger gains in receptive knowledge."

\subsection{Receptive vs. Productive Vocabulary Learning}

Despite the complexity involved in degrees of word knowledge, a number of researchers (Henriksen, 1999; Meara, 1990; Nation, 2001) proposed a two-category framework for vocabulary knowledge, i.e. the reception/production distinction, which can be viewed as a practical pedagogical application in assessing vocabulary rather than as representing how vocabulary knowledge is acquired in reality. A number of studies suggested a few attributes regarding the relationship between reception and production: (1) the receptive vocabulary is larger than the productive vocabulary (Melka, 1997; Laufer, 1998); (2) reception precedes production (Melka, 1997); (3) production is more difficult than reception (Griffin and Harley, 1996; Waring, 1997; Mondria and Wiersma, 2004).

It is generally agreed that the learning of receptive or productive knowledge can be explained by the transfer-appropriate processing (TAP) theory that suggests that words processed receptively result in better receptive knowledge and those processed productively result in better productive knowledge (Bransford, Franks, Morris and Stein, 1979). A number of lexical studies on either individual words (Griffin and Harley, 1996; Waring, 1997; Mondria and Wiersma, 2004; Shintani, 2011) or lexical phrases/idioms (Steinel, Hulstijn and Steinel, 2007) lend support to this view, i.e. receptive learning is more compatible for receptive knowledge and productive learning more suitable for productive knowledge. 
In parallel grammatical studies, similar results have been obtained, as shown by Dekeyser (1997), DeKeyser and Sokalski (2001), Tanaka (2001) and De Jong (2005).

However, all the lexical studies cited above, except the one by Shintani (2011) that investigated the receptive and productive learning effects, simply employed de-contextualized word-pair list learning as the sole learning activity. More specifically, learning the L2-L1 list is treated as receptive learning as it requires the learner to retrieve a more familiar L1 word cued by an L2 equivalent while learning the L1-L2 list is a productive task which requires the learner to retrieve a less familiar L2 word cued by a more familiar L1 word. In addition, all the learning tasks were completed in rather a short fixed period of time of up to 15 minutes. Such de-contextualized list learning does not represent the authentic way in which most vocabulary is learned, thus being of limited value for instructional pedagogy. Examining the receptive and productive learning effect with more contextualized vocabulary learning activities/exercises would be more meaningful and pertinent. Although the study by Shintani (2011) employed both receptive and productive exercises rather than the list learning, the exercises are either aural or oral in nature but not based on a reading text.

\subsection{Research Questions}

As we can see, the studies reviewed above mainly involve adults (university students) or young adults (senior secondary school pupils) and a lack of attention to young learners is evident. If reading plus exercises can prove to be effective with pupils, teachers are provided with a common yet very useful instructional pedagogy as an alternative to teaching vocabulary. In the current study, following fully contextualized reading, different types of vocabulary exercises are designed for L2 young learners to practise target items. Receptive exercises include giving or matching definitions for new items while productive exercises comprise gap filling and sentence writing. This study seeks to provide answers to the following research questions:

1. Do reading-based exercises help L2 young learners acquire new vocabulary?

2. How do receptive learning and productive learning affect L2 young learners' vocabulary retention?

\section{3. Мethod}

\subsection{Participants}

The participants in this quasi-experimental research were a class of 25 primary three (P.3) pupils taught by one of the researchers in a Hong Kong primary school where Chinese is used as the medium of instruction except for English courses. There were 14 boys and 11 girls, aged 8 to 9 . Most of these pupils would have learned English as their first L2; they usually had an English lesson of half an hour to an hour every weekday. Due to practical constraints, it was difficult to access other groups of pupils of the same level, so a withinsubjects design was adopted, i.e. each pupil experienced both learning conditions (reading followed by receptive or receptive + productive exercises). 


\subsection{Instruments}

There were two types of instruments in this research: four short reading texts with vocabulary exercises developed by the researchers as the instructional instrument (the independent variable) and a test adapted from the Vocabulary Knowledge Scale (VKS) as the testing instrument (the dependent variable). The four reading texts were chosen from supplementary learning materials which were semantically related to the topics of the textbook used by the pupils during the experimental period. The texts were slightly modified (e.g. change of complex sentence structures or substitution of difficult words) to ensure that pupils could understand these texts. Each of the texts was about 100 words long, matching the normal length of the texts used in their textbooks. 20 new content words (nouns, verbs and adjectives) were inserted or substituted in the four texts, 5 words being in each text. All these words were assumed to be unknown to the pupils based on the teacher's knowledge of the pupils. In addition, all these words, except one, occurred beyond the first 1000-word frequency. No pre-test was given which might alert pupils to the nature of the study, which in turn might affect the results.

The Vocabulary Knowledge Scale (VKS) developed by Wesche and Paribakht (1997) was adapted and translated into the L1 to measure pupils' vocabulary development in the current study. The original 5-point scale was modified to a 3-point scale for two reasons. First, as Bruton (2009) has pointed out, some of the scales may not be well differentiated, e.g. "I think I know it..." (Scale III) and "I know this word..." (Scale IV). Secondly, the participants were fairly young (8-9 years old) and not cognitively mature enough to distinguish the 5 statements from each other. Due to the tight teaching schedule to follow the required school curriculum, pupils could not finish the test on all the 20 items in one lesson (35 minutes), only 16 target items appeared in the test, i.e. 1 out of 5 target items in each text was randomly removed. See Table 1 for the summary of word class information of the 16 words tested in both conditions. Previous research indicated that word class might be a variable that affects word learning difficulty but how exactly is unclear (Folse, 2004). Laufer (1990) tentatively suggested that, among all content words, nouns are the easiest to learn followed by verbs and adjectives while adverbs are the most difficult. Mainly two word classes - nouns and verbs - occurred in the test and they were more or less equally allocated to each condition. See Table 1 for the words and their word class information. After calculating the scores for each participant, a reliability test yielded a fairly high Cronbach Alpha: .914, which is higher than the figure $(.82-.89)$ reported for the original version by Paribakht and Wesche (1997). This indicates that the test had been appropriately adapted and was fairly reliable. See below for an example of a test item translated into English.

\section{Harvest}

1. I don't know this word.

2. I know this word. It means (Chinese translation or English definition).

3. I know how to use this word to make up a sentence. 
Table 1. Information for words tested in each condition

\begin{tabular}{|l|l|l|}
\hline \multicolumn{1}{|c|}{$\begin{array}{c}\text { Word } \\
\text { class }\end{array}$} & \multicolumn{1}{|c|}{ Receptive learning } & \multicolumn{1}{c|}{ Productive learning } \\
\hline Noun & $\begin{array}{l}5 \text { (harvest, lantern, carnival, } \\
\text { exhibition, almond })\end{array}$ & $\begin{array}{l}5 \text { (pumpkin, witch, recipe, bacon, } \\
\text { lettuce) }\end{array}$ \\
\hline Adjective & 0 & 1 (wonderful) \\
\hline Verb & 3 (peel, slice, sprinkle) & 2 (threaten, scare) \\
\hline Total & 8 & 8 \\
\hline
\end{tabular}

Following a similar modified VKS adapted by Folse (2004), pupils' knowledge of each vocabulary item in the current study was scaled from 0 to 2 . " 0 " is the lowest scale, i.e. failing to recognize the word that had been encountered previously. " 1 " would be awarded if the pupils could provide the word meaning (in L1 translation or L2 definition) but failed to produce a sentence. " 2 ", the highest mark, would be awarded to those who could make a sentence using the vocabulary items correctly as well as provide the correct meaning. Later it was discovered that these pupils often could not produce fully grammatically correct sentences. The degree of appropriate meaning expression determined by the collocation involving the target word was the focus and not the grammar of the whole sentence. 2 marks would still be awarded if the meaning could be correctly expressed in the collocation, regardless of other grammatical mistakes in the sentence.

\subsection{Procedure}

This research was conducted over a period of 5 weeks in 5 lessons of 35 minutes each. Two reading-based methods were used to help pupils learn the 20 new vocabulary items. After they had read the texts, they either learnt through receptive learning or through productive learning in different weeks.

In the first week, the receptive learning method was employed. Pupils read a short passage about Festivals and then they were asked to answer three comprehension questions to make sure that they had understood the meaning of the passage. After that, they were asked to read the 5 underlined new words in the text. Pupils were asked to provide the Chinese meaning for each target word in the exercise sheet with the teacher's help. After elicitation of initial guessing of the meanings, pictures shown on PowerPoint and actions performed by the teacher were used to illustrate the meaning of the target items. Then the Chinese definition for each item was shown on the PowerPoint to ensure the correct meanings were understood by the pupils. They were told to match the 5 target words with the corresponding English explanations. Pupils' answers to the exercise were then checked by the teacher.

One week later, pupils were asked to read the second passage, also about Festivals, but this time the productive learning method was adopted after reading. After reading the passage, pupils needed to answer the comprehension questions and provide the Chinese meaning of the 5 target items. Instead of doing the matching definition activity as in the 
receptive condition, they did two productive exercises: gap filling and sentence writing using each new item. These two exercises were used to focus on the productive aspect of vocabulary knowledge. The productive learning condition used one additional exercise and the time needed for completing all tasks was in average 5-6 minutes more than the receptive learning condition. As it is generally agreed that productive learning is much more difficult than receptive learning (Griffin and Harley, 1996; Waring, 1997; Mondria and Wiersma, 2004), it is understandable that the productive learning condition used a little more time than the receptive learning condition.

In the third week, pupils read a passage on food and the same procedure carried out in week 1 was repeated. In the fourth week, pupils read another passage on food and the procedure in week 2 was then repeated. In week 5, an unannounced delayed post-test adapted from the VKS was distributed to pupils who were required to complete the test during the 35-minute lesson. Since the test was administered one week after all instructional sessions, it is fair to assume that the test score represented stable, long-term vocabulary retention.

\subsection{Data analysis}

All pupils' scores were entered into SPSS for statistical tests. A paired samples $t$-test was carried out to measure the within-subjects effect of the two conditions. In addition, the pupils' vocabulary knowledge gain was classified into three types: no knowledge, receptive knowledge and productive knowledge, based on which a chi-square test was performed. These two statistical tests aim to answer the first and second research questions.

\section{Results}

\subsection{Statistical tests}

Table 2 presents the results of the test, showing the mean score and the standard deviation of the vocabulary retention score for each condition.

Table 2. Vocabulary retention of the two conditions

\begin{tabular}{|l|c|c|c|c|}
\hline \multicolumn{1}{|c|}{ Condition } & Mean & Retention rate* & $\begin{array}{c}\text { Standard } \\
\text { Deviation }\end{array}$ & Maximum \\
\hline $\begin{array}{l}\text { receptive } \\
\text { learning }\end{array}$ & 7.68 & $48 \%$ & 3.67 & 16 \\
\hline $\begin{array}{l}\text { productive } \\
\text { learning }\end{array}$ & 11.64 & $73 \%$ & 4.21 & 16 \\
\hline
\end{tabular}

* Retention rate is obtained by dividing the mean score by the maximum score.

From Table 2, it can be seen that both conditions yielded overall satisfactory vocabulary retention ( $7.68-11.64$ out of 16$)$ when reading was followed by exercises, thus providing 
the answer to the first research question, i.e. do reading-based exercises help L2 young learners acquire new vocabulary? In order to answer the second research question, i.e. how do receptive learning (with only receptive exercises) and productive learning (combining both receptive and productive exercises) affect L2 young learners' vocabulary retention? , a comparison of the mean scores show that score for receptive learning (7.68) is considerably lower than that for productive learning (11.64). Accordingly, the retention rate is much higher for productive learning $(73 \%)$ than for receptive learning $(48 \%)$. This suggests that pupils, in general, retain more vocabulary knowledge in the productive learning condition than in the receptive learning condition. A paired samples $t$-test shows that the difference is significant (mean difference $=3.96 ; p<0.001$ ). The Cohen's $d$ is 1.01 , showing a large effect size. It is evident that pupils performed much better in the test items after doing both receptive and productive exercises than only the receptive exercises.

The second research question can also be answered by looking at the type of vocabulary knowledge gained in each condition. All answers were classified into three types: unknown (i.e. scored "0"), receptive (i.e. scored "1") and productive (i.e. scored "2"). See Table 3 for the results. This shows clearly that when receptive exercises are used, students tend to obtain receptive knowledge (52\%) but fall short of productive knowledge; by contrast, when both receptive and productive exercises are used (productive learning), productive knowledge is more likely to be obtained (59\%). A chi-square test indicates that the distribution patterns for both conditions differ significantly from each other $\left[x^{2}(2, \mathrm{~N}=400)=56.87, p<0.001\right]$. See Figure 1 for the different distribution patterns for the receptive learning and productive learning conditions. Notably, the productive learning condition had fewer instances of unknown and receptive knowledge but far more for productive knowledge than the receptive learning condition. If we average the knowledge gain for all pupils, the productive learning condition resulted in 4.64 (118 divided by 25 participants) words productively for each participant while the receptive learning condition resulted in only 1.76 words productively out of the total of 8 words. The number of words that were learned productively in the productive learning condition was almost three times that in the receptive learning condition.

Table 3. Knowledge types in vocabulary retention between the receptive learning and productive learning conditions.

\begin{tabular}{|l|l|l|l|}
\hline & \multicolumn{1}{|c|}{ receptive learning } & \multicolumn{1}{c|}{ productive learning } & \multicolumn{1}{c|}{ Total } \\
\hline Unknown & $52(26 \%)$ & $26(13 \%)$ & $78(19.5 \%)$ \\
\hline Receptive & $104(52 \%)$ & $56(28 \%)$ & $160(40 \%)$ \\
\hline Productive & $44(22 \%)$ & $118(59 \%)$ & $162(40.5 \%)$ \\
\hline Total & $200(100 \%)$ & $200(100 \%)$ & $400(100 \%)$ \\
\hline
\end{tabular}




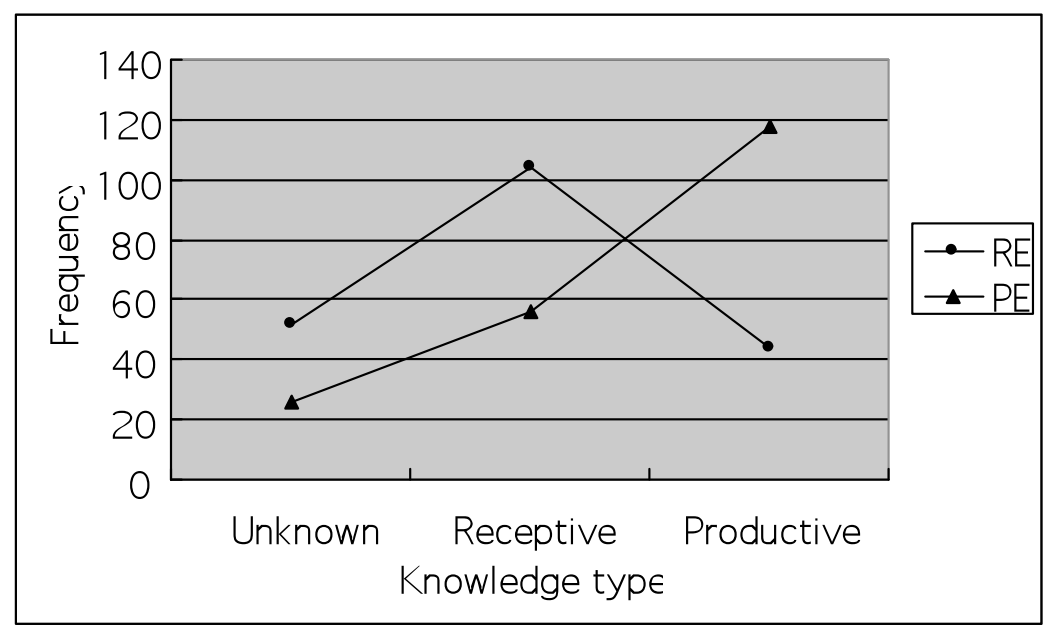

Figure 1: Distribution patterns of vocabulary knowledge types between the receptive learning and productive learning conditions

\section{Discussion}

\subsection{Effectiveness of reading plus exercises on young learners}

Previous research has demonstrated the effectiveness of using reading-based exercises on adult or young adult learners' L2 vocabulary acquisition (Paribakht and Wesche, 1997; Min, 2008; Laufer and Rozovski-Roitblat, 2011). The results of our study have shown that reading-based exercises can also be effective for young learners and the retention rate is quite satisfactory, pupils being able to retain $48 \%-73 \%$ of the vocabulary in the delayed post-test. Thus the current research adds to our understanding of the usefulness of readingbased exercises in terms of younger learners' L2 vocabulary acquisition. This is encouraging news for the vast number of primary school teachers in that the reading-based vocabulary instructional method can also work for young learners in primary schools as an alternative to other popular methods for teaching vocabulary such as repetition or dictation. As demonstrated in this study, the teacher played a key role in guiding and instructing pupils during the whole learning process; it was the teacher who drew pupils' attention to the unknown items in the reading texts and helped them understand the word meaning as well as practise using the words with various exercises. Young learners, who are not cognitively mature, need clear instructional guidance from the teacher when they are required to learn new vocabulary items from reading-based lessons.

\subsection{The effects of reading-based receptive and productive learning}

This research also investigated how reading-based receptive and productive learning, implemented by different types of exercises, affect pupils' vocabulary retention and knowledge 
types. Both the mean scores and the paired samples $t$-test show that the productive learning condition outperformed the receptive learning condition in the delayed post-test, the score for the former being almost twice that of the latter. The chi-square test demonstrates clearly that when both receptive and productive exercises follow reading, this is much more likely to lead to productive knowledge than receptive knowledge alone; each pupil has on average learned almost three times more words productively in the productive learning condition than in the receptive learning condition. This suggests that pupils generally have acquired many more vocabulary items and far better productive knowledge in the productive learning condition than in the receptive learning condition. This may be due to the fact that pupils had to use the target items in gap filling or sentence making in the productive exercises; they were forced to pay attention to various lexical aspects, such as spelling and collocations, in addition to meaning. Our study employed contextualized reading to investigate the effects of receptive and productive learning; the results corroborate what Mondria and Wiersma (2004: 98) suggested: "When the learning aim is both receptive and productive word knowledge, it is recommended to learn the words both receptively and productively". The results of our study are also in line with those of Webb's (2005) second experiment in which a within-subjects design (the same as in our study) was used; Webb's university participants demonstrated more satisfactory vocabulary retention in the productive condition than in the receptive condition. If Mondria and Wiersma (2004) and Webb (2005) supported the transfer-appropriate processing (TAP) in de-contextualized learning studies, our study lends evidence to support the same view in fully contextualized reading-based vocabulary learning. In addition, our research focused on much younger L2 learners and demonstrated convincingly that they can benefit more if productive learning follows contextualized reading. Primary school teachers are encouraged to adopt both receptive and productive exercises after reading rather than simply receptive exercises which are likely to lead to vocabulary recognition only.

\subsection{Limitations of the study}

Due to the practical constraints faced by the current study, teachers or researchers who would like to conduct similar research in future need to be alerted to a number of limitations. First of all, this is a small-scale investigation and the results may be biased due to the small sample size. A study involving more participants is desired in order that the results may be generalized more confidently. Secondly, time is not strictly controlled in this quasi-experimental study, i.e. pupils in the productive learning condition spent slightly more time completing all the exercises than in the receptive condition. On the other hand, this perhaps reflects the different nature of receptive and productive learning, namely, the latter is more difficult and hence needs a little more extra time. Our primary concern is not to compare and find out which type of exercise, receptive or productive, is more effective, as in a strictly controlled experiment, but to offer teachers a clear understanding of how receptive and productive exercises can complement each other to promote pupils' vocabulary acquisition to a productive level in a real classroom situation.

In addition, it is found that pupils made grammatical mistakes frequently when using the target items to write sentences. Although some of the sentences were comprehensible, they contain grammatical mistakes to varying degrees. This suggests that not all primary three 
pupils (at least in our sample) were able to produce fully grammatically correct sentences when they attempted to use the newly learned item, possibly due to their under-developed grammatical system. In this sense, asking them to make up a sentence with the target word may not be the ideal way to test their productive knowledge. Despite a rather high reliability reported by the modified version of the Vocabulary Knowledge Scale (VKS) used in the current study, it is tentatively suggested that the highest scale - sentence writing - is not suitable for young learners or low level learners and may be replaced by collocating the target words.

\section{Conclusion}

Using five naturally occurring lessons for a group of Primary three pupils, this teacherinitiated classroom study documented how reading-based lessons could be conducted to teach young learners L2 vocabulary from meaning recognition to using the word in a sentence context. To ensure pupils' mastering of target items to a productive level, both receptive and productive exercises are needed. Young learners at this stage have great difficulties in learning and using verbs accurately. Such difficulties can be partially attributed to learners' L1 influence (as in this study) and partially to the L2 verbs' own complexity. Considering young learners' relatively lower cognitive capacity than that of adult learners, teachers should teach verbs in chunks as well as create opportunities for young learners to meet the target word in contexts different from the original context. Attention should be paid to variant morphological forms of verbs and the context in which they should be used. Reading-based vocabulary text exercises prove to be an effective way to help young learners learn vocabulary, but the importance of more communicative oral activities/tasks in facilitating vocabulary use should not be underestimated. Future studies should focus on how text-based exercises and oral activities can be synergized to promote young learners' L2 vocabulary learning.

\section{REFERENCES}

Bransford, J. D., Franks, J. J., Morris, C. D., and Stein, B. S. (1979). "Some general constraints on learning and memory research", in L. S. Cermak and F. I. M. Craik (eds.), Levels of processing in human memory. Mahwah, NJ: Erlbaum, 331-354.

Brown, R., Waring, R., and Donkaewbua, S. (2008). "Incidental vocabulary acquisition from reading, reading-while-listening, and listening to stories", in Reading in a Foreign Language, 20: 136-63.

Bruton, A. (2009). "The vocabulary knowledge scale: a critical analysis", in Language Assessment Quarterly, 6, 4: 288-297.

De Jong, N. (2005). "Can second language grammar be learned through listening? An experimental study", in Studies in Second Language Acquisition, 19: 195-221.

DeKeyser, R. (1997). "Beyond explicit rule learning: Automatizing second language morphosyntax", in Studies in Second Language Acquisition, 19: 195-221.

DeKeyser, R., and Sokalski, K. J. (2001). "The differential role of comprehension and production", in Language Learning, 51, s1: 81-112. 
Folse, K. S. (2004). "The effect of type of written exercise on L2 vocabulary retention", in TESOL Quarterly, 40, 2: 273-293.

Griffin, F. and Harley, T. A. (1996). "List learning of second language vocabulary", in Applied Psycholinguistics, 17: 443-460.

Henriksen, B, (1999). "Three dimensions of vocabulary development", in Studies in Second Language Acquisition, 21: 303-317.

Hill, M. and Laufer, B. (2003). "Type of task, time-on-task and electronic dictionaries in incidental vocabulary acquisition", in International Review of Applied Linguistic, 41, 2: 87-106.

Horst, M. (2005). "Learning L2 vocabulary through extensive reading: A measurement study", in The Canadian Modern Language Review, 61: 355-82.

Horst, M., Cobb, T. and Meara, P. (1998). "Beyond a Clockwork Orange: Acquiring second language vocabulary through reading", in Reading in a Foreign Language, 11, 2: 207-223.

Hulstijn, J. (2005). "Incidental learning and intentional learning", in J. Doughty, M. L. Long (eds), The handbook of second language acquisition. Blackwell Publishing Ltd, 349-381.

Huckin, J. and Coady, J. (1999). "Incidental vocabulary acquisition in a second language", in Studies in Second Language Acquisition, 21, 2: 181-193.

Hulstijn, J., Hollander, M. and Greidanus, T. (1996). "Incidental learning by advanced foreign language students: the influence of marginal glosses, dictionary use, and reoccurrence of unknown words", in The Modern Language Journal, 80: 327-339.

Laufer, B. (1990). "Why are some words more difficult than others? Some intralexical factors that affect the learning of words", in International Review of Applied Linguistics in Language Teaching, 28, 4: 293-307.

Laufer, B. (1998). "The development of passive and active vocabulary in a second language: same or different?", in Applied Linguistics, 19, 2: 255-271.

Laufer, B. (2006). "Comparing focus on form and focus on forms in second-language vocabulary learning", in The Canadian Modern Language Review, 63: 149-166.

Laufer, B. and Rozovski-Roitblat, B. (2011). "Incidental vocabulary acquisition: The effects of task type, word occurrence and their combination", in Language Teaching Research, 15, 4: 391-411.

Nagy, W. E., Herman, P. A. and Anderson, R. C. (1985). "Learning words from context", in Reading Research Quarterly, 20: 233-253.

Mason, B. and Krashen, S. (1997). "Extensive reading in English as a foreign language", in System, 25: 91-102.

Meara, P. (1990). "A note on passive vocabulary", in Second Language Research, 6, 2: 150-154.

Melka, F. (1997). "Receptive vs. productive aspects of vocabulary", in N. Schmitt, and M. McCarthy (eds.), Vocabulary: Description, acquisition and pedagogy. Cambridge: Cambridge University Press, 84-102.

Min, H. T. (2008). "EFL vocabulary acquisition and retention: reading plus vocabulary enhancement activities and narrow Reading”, in Language Learning, 58, 1: 73-115.

Mondria, J.A. and Wiersma, B. (2004). "Receptive, productive, and receptive + productive L2 vocabulary learning: What difference does it make?", in P. Bogaards, and B. Laufer (eds.), Vocabulary in a Second Language: Selection, Acquisition and Testing. Amsterdam: Benjamins, 79-100.

Nation, I. S. P. (2001). Learning vocabulary in another language. Cambridge: Cambridge University Press.

Paribakht, T. S. and Wesche, M. (1997). "Vocabulary enhancement activities and reading for meaning in second language vocabulary development”, in J. Coady and T. Huckin (eds.), 
Second language vocabulary acquisition: A rationale for pedagogy. New York: Cambridge University Press, 174-200

Pellicer-Sánchez, A. and Schmitt, N. (2010). "Incidental vocabulary acquisition from an authentic novel: do things fall apart?", in Reading in a Foreign Language, 22: 31-55.

Pitts, M., White, H. and Krashen, S. (1989). "Acquiring a second language through reading: a replication of the Clockwork Orange study using second language acquirers", in Reading in a Foreign Language, 5, 2: 271-275.

Shintani, N. (2011). "A comparative study of the effects of input-based and production-based instruction on vocabulary acquisition by young EFL learners", in Language Teaching Research, 15, 2: 137-158.

Sonbul, S. and Schmitt, N. (2010). "Direct teaching of vocabulary after reading: is it worth the effort?", ELT Journal, 64, 3: 253-260.

Steinel, M. P., Hulstijn, J. and Steinel, W. (2007). "Second language idiom learning in a pairedassociate paradigm: Effects of direction of learning, direction of testing, idiom imageability, and idiom transparency", in Studies in Second Language Acquisition, 29, 3: 449-484.

Sternberg, R. J. (1987). "Most vocabulary is learned from context", in M. G. McKeown, and M. E. Curtis (eds.), The nature of vocabulary acquisition. New Jersey, London: Lawrence Erlbaum Associates, Publishers, 89-105

Tanaka, T. (2001). "Comprehension and production practice in grammar instruction: Does their combined use facilitate second language acquisition?", in Japan Association of Language Teaching Journal, 23, 1: 6-30.

Waring, R. (1997). "A study of receptive and productive vocabulary learning from word cards", in Studies in Foreign Languages and Literature (Notre Dame Seishin University), 21, 1: 94-114.

Waring, R. and Takaki, M. (2003). "At what rate do learners learn and retain new vocabulary from reading a graded reader?", in Reading in a Foreign Language, 15: 130-60.

Webb, S. (2005). "Receptive and productive vocabulary learning: The effects of reading and writing on word knowledge", in Studies in Second Language Acquisition, 27: 33-52. 